I Universidade Federal de Minas Gerais (UFMG), Faculdade de Letras,

Belo Horizonte, MG, Brasil

eneidamariasouza@gmail.com

https://orcid.org/oooo-0002-5018-493I

Eneida Maria de Souza'

\title{
ARQUIVOS EM MOVIMENTO
}

Süssekind, Flora; Dias, Tânia (orgs.). Cultura brasileira

hoje: diálogos. Rio de Janeiro: Fundação Casa de Rui

Barbosa, 2018. 3 v.

A publicação de três vultosos volumes intitulados Cultura brasileira hoje: diálogos, pela Fundação Casa de Rui Barbosa, traduz um esforço coletivo em entregar ao público um painel significativo da produção artística e intelectual da atualidade. Como resultado de eventos organizados em torno de depoimentos e debates realizados na instituição entre 2004 e 20I7, aos artistas, escritores e críticos, reunidos em duplas, lhes foi dada a oportunidade de expor experiências e metodologias de trabalho. A original organização das exposições e debates reuniu representantes de diferentes áreas, como literatura, artes plásticas, cinema, fotografia, arquitetura, dança, teatro, cenografia, música e crítica. Na proposta apresentada, motivada pela necessidade de criar um diálogo entre manifestações artísticas distintas, pela troca de experiências e possíveis entrosamentos já existentes ou por existir, registra-se a rica contribuição dessa publicação para o público leitor.

O envolvimento de enorme contingente de pessoas - entre organizadores, entrevistadores, autores, revisores, bolsistas, pesquisadores da obra iconográfica e fotográfica - fornece a dimensão da edição dos volumes em 20I8, compondo-se de 2.000 laudas e 2.440 notas de pé de página. Minibiografias de nomes citados durante os diálogos refletem e justificam, nos rodapés, o empenho pelo trabalho arquivístico e pelo teor historiográfico da publicação. Trata-se de um repertório de referências de alto nível acadêmico, respeitando-se a multiplicidade e a heterogênea produção artística da atualidade, que se projeta no interior de uma instituição 
pública de renome, responsável pela preservação de arquivos de escritores e intelectuais: um Museu que se revitali$\mathrm{za}$, abrindo as portas para a comunidade. Os relatos de vida, a experiência comum entre pessoas de iguais e diferentes gerações, o encontro inusitado entre aqueles que nunca se haviam encontrado, a aproximação entre técnicas e processos criativos transformam-se em atraentes narrativas biográficas, de leitura agradável e instrutiva. As aventuras relatadas pelos protagonistas, sejam elas em estágios, exílios voluntários ou não no exterior, perseguições políticas ou ampliações do campo de pesquisa artística com parcerias em outras áreas, endossam o deslocamento como base de um painel cultural em movimento, revelador de potencialidade e vigor produtivo.

Merece ainda ser ressaltado o fórum de debates criado por ocasião dos eventos, em que especialistas de múltiplos campos de saber foram convocados ao diálogo, resultando no aprimoramento das relações interdisciplinares, uma vez que o espaço de discussão se distinguia dos apressados locais reservados aos encontros em festivais, feiras ou congressos mais especializados. A oportunidade reservada aos autores quanto à exposição e reflexão sobre os exercícios criativos encontrou solo propício para descobertas inauditas, coincidências no tratamento de procedimentos artísticos e literários, além de tornar pública sua metodologia de trabalho, com as inquietações e empecilhos aí inerentes. Compartilhar com o leitor momentos de extrema produtividade, principalmente originada nos bastidores das conversas ou nos encontros, guiados por afinidades estéticas, converte-se na exposição de diversos saberes que circulam e circularam nas últimas décadas no país.

Diante do número significativo de convidados aos diálogos interdisciplinares, reunidos na publicação em três volumes (62 autores, organizados em 3I duplas), a leitura deverá obrigatoriamente se efetuar com vistas à escolha de cada um. A participação desenvolta e oralizada dos depoimentos não impede ter a edição aspecto enciclopédico, pela pretensão de englobar tendências distintas e heterogêneas no âmbito artístico e noutras áreas, ao oferecer um painel cultural de relevância para o entendimento da complexa situação das artes nos dias de hoje. O aspecto enciclopédico, contudo, afasta-se de um conceito fechado, ilustrativo e globalizante, ao se inscrever como aleatório e fragmentário, em que são discutidos, entre muitos, os procedimentos criativos; os níveis de aprendizagem entre os pares; a pesquisa referente ao trabalho de criação; o engajamento da obra como reflexão nacional, aliado ao compromisso com o olhar cosmopolita. O número de autores implica, portanto, a variedade infindável de temas e conceitos aí focalizados, o que permite considerar a publicação texto de referência para o infindável contingente de leitores.

Na seleção dos autores, as organizadoras justificam a ausência de nomes das várias regiões do país, em virtude de dificuldades financeiras da instituição, da recusa aos convites por parte de muitos artistas, por não admitirem a discussão de seu trabalho artístico. Nesse sentido, o núcleo de participantes se 
restringiu ao eixo Rio-São Paulo, embora a questão geográfica não pudesse servir de parâmetro, uma vez que muitos deles vieram de outras estados e se estabeleceram nas capitais. Tal restrição, entretanto, não deixa de ser exclusiva com determinada parcela dos representantes das artes no Brasil. No entanto, percebe-se que a historiografia artística não se pauta mais por classificações de ordem temporal e espaçogeográfica, desobedecendo critérios cronológicos e se impondo no fluxo anacrônico das manifestações. A composição dos diálogos em duplas, embora não tenha seguido obrigatoriamente representantes da mesma geração, conseguiu reordenar tendências, agrupar escritores com artistas plásticos, cineastas com críticos literários, cenógrafos/diretores de teatro com poetas, fotógrafos com escritores, e assim por diante. Se o perfil recaísse na produção de uma historiografia ortodoxa, a organização do evento iria manter as áreas separadas, a estrutura cronológica, a conformidade geracional e a semelhança de estilos.

Se fosse solicitado definir um eixo teórico/temático para as discussões e para a proposta em geral, o termo deslocamento poderia ser o escolhido, acompanhado do desejo dos autores de registrar o procedimento artístico/crítico de suas realizações. O deslocamento de áreas específicas em direção a outras, a quebra da autonomia autoral e, consequentemente, da obra, o apelo à alteridade e à múltipla contaminação de discursos se aliam ao movimento contínuo das viagens em direção ao desconhecido e ao novo. Expor as experiências e os bastidores da produção artística/crítica não deixa de ser atividade contemporânea, junção de criação e crítica, ficção e ciência, experimentação e procedimento, ensaio e filme, documento e ficção.

O primeiro volume se inicia com a presença do escritor Silviano Santiago em parceria com Anna Maria Maiolino, artista plástica e poeta, registrada em 2004; o último, em 2017, fechando a série, com o diálogo entre o crítico de cinema Carlos Alberto Mattos e Erick Rocha, diretor de cinema (por sinal o mais longo dos textos). A distância temporal entre todos os depoimentos não lhes diminui a importância, pois, registrando diferentes momentos da situação cultural do país, acenam para uma visão englobante e contrastiva, incluindo aí um repertório de gerações bastante diversificadas. Por se constituir enquanto publicação de múltiplas entradas, Cultura brasileira hoje: diálogos atende a interesses distintos, o que comprova o aspecto enciclopédico e englobante dos volumes. Entre poetas, escritores, artistas plásticos, críticos literários, teatrais, artísticos, cenógrafos, cineastas músicos, diretores de fotografia, arquiteto, dançarinos, cientista, diretores teatrais, encena-se um diálogo polifônico, no qual prevalece o esforço em discutir escolhas estéticas e mecanismos empregados na criação. ${ }^{I}$ Configuram-se, em todos os depoentes, o compromisso com a palavra política e a imagem transgressora, a performance artística como prova de engajamento com a proposta social, a pesquisa sempre renovada com os materiais de criação.

No desenrolar dos depoimentos e questões levantadas pelos participantes, destacam-se alguns temas comuns: 
o trabalho artístico como resultado do empenho arquivístico, da pesquisa em torno de novos/antigos objetos, formação responsável pela concepção da arte como artifício e experimentação. Em consonância com o espaço reservado aos debates - a Fundação Casa Rui Barbosa, guardiã de arquivos e bibliotecas -, a reflexão sobre o tema reforça a importância de se considerar o processo criativo de forma crítica e teórica. Silviano Santiago, professor, escritor e ensaísta, transita entre lugares discursivos, 0 ensaio e a ficção, a pesquisa e o arquivo, o que confirma seu perfil de escritor crítico. Rosângela Rennó, "colecionadora compulsiva" de material fotográfico, realiza um trabalho de apropriação do material que recolhe, transformando-o em arte própria. Carlos Vergara, na sua aventura artística, sai em busca dos minérios, dos pigmentos do Brasil em Minas Gerais, materiais importantes para o entendimento de sua pintura, um trabalho marcado pela apropriação e a recriação. Sílvio Tendler, possuidor de arquivo inestimável de imagens cinematográficas, é conhecido como "colecionador de imagens", acervo imprescindível na confecção de muitos de seus documentários. E assim se comportam igualmente outros entrevistados, entendendo serem os ofícios resultados de pesquisa e manuseio de materiais de toda sorte.

No cômputo geral dos depoimentos publicados, constata-se o efeito de deslocamento do objeto artístico de sua autonomia, registrado, por exemplo, por Sérgio Sant'Anna (2018, v. I: 434), "O texto está querendo ser visual, dramático. Buscar algo que esteja fora da literatura é minha obsessão textual"; ou por
Bernardo Carvalho (20I8, v.I: I24), ao assumir a mudança na sua maneira de criar ficção: "O que aconteceu com Nove noites foi um processo muito particular: quando li um artigo de jornal, tive uma espécie de epifania. Não sei por que o artigo bateu de um jeito muito forte. Com este livro, comecei a pesquisar para fazer ficção, o que nunca tinha feito antes". Carlos Alberto Mattos (2018, v. 3: 687), crítico de cinema, discorre sobre o filme-ensaio, o qual, diferentemente dos documentários convencionais, retrata a busca de um cinema político, de invenção, "que trabalha com imagens de arquivo, que reativa a memória, que reinterpreta o passado de modos surpreendentes, que reinventa o passado e o presente".

Ao leitor, a oportunidade de entrar nesse arquivo-texto, de modo atento e disposto a usufruir do rico material bibliográfico que tem em mãos. Ocasiões como essas, promovidas por órgãos de pesquisa e de divulgação de saberes multidisciplinares, acontecem raramente no meio acadêmico, devido à constante precariedade orçamentária aliada à má vontade em incentivar debates culturais e políticos dessa natureza.

Recebida 20/8/2019

Aprovado I9/9/2019 


\section{NOTA}

I participantes foram organizados em duplas, seguindo, na publicação, a seguinte ordem: Volume I: Anna Maria Maiolino/Silviano Santiago; Ana Carolina/Antonio Dias; Angelo Venosa/Bernardo Carvalho; Rodrigues/Zé Celso Martinez Corrêa; Mario Novello/ Paulo Mendes da Rocha; Rosangela Rennó/Sergio Sant'Anna; Nuno Ramos/Vilma Arêas. Volume 2: André Sant'Anna/Bia Lessa; Anna Bella Geiger/Juliana Carneiro da Cunha; Beatriz Bracher/Carlito Carvalhosa; Carlito Azevedo/Waltercio Caldas; Carlos Süssekind/Mário Carneiro; Carlos Zilio/Cássio Loredano; Eduardo Escorel/Paulo Henriques Brito; Elizabeth Jobim/João Saldanha; Milton Machado/Rodolfo Caesar; Sílvio Tendler/ Walnice Nogueira Galvão. Volume 3: Antonio Manuel/Jean-Claude Bernadet; Antonio Geraldo Figueiredo Ferreira/ Luiz Costa Lima; Antônio Araújo/ Sílvio Ferraz; Daniella Thomas/Lu Menezes; Eduardo Sued/Paulo Sergio Duarte; Flávia Meireles/Marília Garcia; Hélio Eichbauer/Tato Taborda; José Resende/Ronaldo Brito; Laura Vinci/Murilo Salles; Milton Hatoum/ Verônica Stigger; Carlos Alberto Mattos/Erick Rocha.

Eneida Maria de Souza é professora emérita e titular da Universidade Federal de Minas Gerais (UFMG), tendo como áreas de interesse: teoria da literatura, literatura comparada e modernismo brasileiro. É autora de Janelas indiscretas(20I I); coautora, com Marília Cardoso, de Modernidade toda prosa (20I4) e organizadora de Mário de Andrade \& Henriqueta Lisboa - correspondência (20I0).

\section{REFERÊNCIAS BIBLIOGRÁFICAS}

Carvalho, Bernardo. (2018). Angelo Venosa/Bernardo Carvalho. In: Dias, Tania; Süssekind, Flora. (Orgs.). Cultura brasileira hoje: diálogos. Rio de Janeiro: Fundação Casa de Rui Barbosa, v. I. Mattos, Carlos Alberto. (2018). Carlos Alberto Mattos/Erik Rocha. In: Dias, Tania; Süssekind, Flora.(Org.). Cultura brasileira hoje: diálogos. Rio de Janeiro: Fundação Casa de Rui Barbosa, v. 3.

Sant'Anna, Sérgio. (20I8). Rosângela Rennó/Sérgio Sant'Anna. In: Dias, Tania; Süssekind, Flora.(Org.). Cultura brasileira hoje: diálogos. Rio de Janeiro: Fundação Casa de Rui Barbosa, v. I. 